\title{
Kesempurnaan Allah Sebagai Dasar Edukasi Pola Hidup Kekristenan
}

\author{
Yakub Hendrawan Perangin Angin \\ Sekolah Tinggi Teologi Ekumene, Jakarta \\ yakubhendrawan@sttekumene.ac.id \\ Tri Astuti Yeniretnowati \\ Sekolah Tinggi Teologi Ekumene, Jakarta \\ triastuti@sttekumene.ac.id
}

\begin{abstract}
Not many Christian lifestyle education that clearly captures the meaning of the call to life to be perfect like the Father in the practice of daily life as believers. With a complete and practical explanation, it is hoped that believers can understand and take a commitment to live a perfect Christian lifestyle like the Father. This study uses a literature review method, namely by analyzing the perfect concept such as the Father as a standard concept framework and Christian lifestyle as a direction for the development and Christian Religious Education. The results of this study demonstrate the concept and implications for the direction of Christian education in generating and shaping Christian life toward perfection as the Father. The finding of this research are: First, Has intelligence and rigor spiritual. Second, Life is blameless and blameless. Third, live by fulfilling God's demands. Fourth, live with quality faith. Fifth, Life like Jesus. Sixth, live according to God's will. Seventh, a life pleasing to God. Eighth, Live with a new mindset. Ninth, Live with extraordinary behavior.
\end{abstract}

Keywords: Christian Living Standard, Perfect Like a Father, Christian Education Pattern

\begin{abstract}
Abstrak
Pendidikan pola hidup orang Kristen belum banyak yang menangkap jelas makna dari panggilan hidup agar sempurna seperti Bapa dalam praktik kehidupan sehari-hari sebagai umat orang percaya. Dengan penjelasan yang lengkap dan praktis membumi diharapkan orang percaya dapat memahami dan mengambil komitmen untuk menjalani pola hidup kekristenan yang sempurna seperti Bapa. Penelitian ini menggunakan metode tinjauan pustaka, yaitu dengan cara menganalisis tentang konsep sempurna seperti Bapa sebagai sebuah kerangka konsep standar dan pola hidup Kristen sebagai arah bagi pengembangan dan Pendidikan Agama Kristen. Hasil dari penelitian ini menunjukkan konsep dan implikasi bagi arah Pendidikan Agama Kristen dalam membentuk orang Kristen yang hidupnya menuju sempurna seperti Bapa. Temuan dari penelitian ini adalah: Pertama, Memiliki kecerdasan dan ketelitian rohani. Kedua, Hidup tidak bercacat dan tidak bercela. Ketiga, Hidup dengan memenuhi tuntutan Allah. Keempat, Hidup dengan iman yang berkualitas. Kelima, Hidup yang serupa dengan Yesus. Keenam, Hidup sesuai kehendak Allah. Ketujuh, Hidup yang berkenan kepada Allah. Kedelapan, Hidup dengan pola pikir baru. Kesembilan, Hidup dengan kelakuan yang luar biasa
\end{abstract}

Kata-kata kunci: Standar Hidup Kristen, Sempurna Seperti Bapa, Pola Pendidikan Kristen 


\section{PENDAHULUAN}

Permasalahan utama dalam kehidupan orang-orang percaya tidak lain adalah tidak sejalannya apa yang diimani dengan peraga kelakuan yang ditunjukkan dalam perilaku sehari-hari. Banyak orang berpendapat bahwa ketika ada orang yang ucapannya mengandung nilai-nilai kristiani dan mempercayai hal-hal yang rohani sudah dapat dipastikan bahwa orang itu pasti selamat dan masuk surga. Yesus memanggil seseorang bukan untuk mengurusi dosa-dosa saja tetapi guna berubah seturut dengan desain Allah, yaitu serupa dan segambar dengan Allah. Orang percaya dipanggil untuk sungguhsungguh memancarkan karakter Yesus sebagaimana dilukiskan dalam Injil dan Filipi 2:5-8. Orang Kristen diminta untuk memperagakan karakter itu dan memengaruhi semua orang seperti yang Yesus sudah teladankan. ${ }^{1}$

Hari ini banyak orang percaya merasa telah memiliki Tuhan, tetapi sebenarnya banyak orang percaya tidak memiliki apa yang Tuhan Yesus ajarkan. Merasa sudah beriman kepada Tuhan Yesus tetapi tidak mengerti apa yang diajarkan. Bagaimana bisa dikatakan

\footnotetext{
${ }^{1}$ Bill Hull, Choose The Life, 2nd ed. (Surabaya: Literatur Perkantas Jawa Timur, 2015).

2 Erastus Sabdono, "Panggilan Khusus," in Panggilan Khusus: Panggilan Untuk Menjadi
}

beriman kalau tidak mengerti apa yang Kristus inginkan. Kebodohan banyak orang Kristen ini, bagian dari salah satu keberhasilan dari tipu muslihat Iblis yang sangat efektif merusak kehidupan iman Kristen yang murni. Salah satu ciri dari orang Kristen yang telah disesatkan adalah selalu memungut ayat-ayat Perjanjian Lama tanpa memperhatikan konteksnya. Dalam hal ini orang percaya harus membedakan pengertian Firman Tuhan bagi umat Perjanjian Lama dan Firman Tuhan bagi umat Perjanjian Baru. Umat Perjanjian Lama memahami Firman Tuhan terkait atau berorientasi terkait hukum dan kebijaksanaan untuk menjadi umat yang bermoral hukum. Sedangkan untuk umat Perjanjian Baru berorientasi pada pengertian terhadap kebenaran untuk menjadi sempurna seperti Bapa. ${ }^{2}$

Arah dari iman Kristen adalah agar orang percaya yang menyatakan menerima Yesus Kristus yang sudah mati dan bangkit pada hari ketiga sebagai Tuhan dan Juru Selamatnya dapat mengalami perubahan baik dalam cara berpikir maupun gaya hidup, dengan sasaran yang jelas menuju sempurna seperti Bapa dan serupa seperti Yesus. ${ }^{3}$

Sempurna Seperti Bapa, ed. Tim Truth Literature, 1st ed. (Jakarta: Rehobot Literature, 2018), 1-4.

${ }^{3}$ Erastus Sabdono, Bekal Kekekalan, 1st ed. (Jakarta: Rehobot Literature, 2019). 
Serupa seperti Yesus dan sempurna seperti Bapa merupakan tujuan iman orang percaya. Ironis sekali bahwa, banyak teolog Kristen yang memandang bahwa hal menjadi serupa dengan Yesus dipandang sebagai sesuatu yang tidak akademis dan tidak memiliki nilai ilmiah teologis. ${ }^{4}$ Padahal justru menjadi serupa seperti Kristus dan sempurna seperti Bapa tidak lain merupakan jantung kekristenan itu sendiri. Penyesatan ini menjadi penyebab dari kemunduran kekristenan selama ratusan tahun. Kekristenan telah menjadi lembaga agama yang sarat dengan unsur-unsur liturgi, perdebatan doktrin teologis, dan Allah menjadi objek penelitian yang hanya ditulis di atas kertas. $^{5}$ Orang-orang percaya, walau hanya jemaat biasa yang tidak pernah mengenyam pendidikan teologi dan tidak pernah disahkan sinode sebagai pejabatnya, tetapi bila mereka memiliki pengalaman langsung dengan Allah, menerima sengatan Allah, maka hidupnya menjadi sangat berkualitas. Seharusnya, inilah yang menjadi ukuran kualitas hidup kekristenan. ${ }^{6}$ Terlebih hal itu diaktualisasi

\footnotetext{
${ }^{4}$ Erastus Sabdono, Berjalan Dengan Allah, 1st ed. (Jakarta: Rehobot Literature, 2021), 52.

5 Ibid.

${ }^{6}$ Sabdono, Berjalan Dengan Allah.

${ }^{7}$ Reni Triposa, Yonatan Alex Arifianto, and Yudi Hendrilia, "Peran Guru PAK Sebagai Teladan Dalam Meningkatkan Kerohanian Dan Karakter Peserta Didik," Jurnal Pendidikan
}

bagi pedoman kekristenan dalam menyatakan iman Kristen yang menjadi pola tuntunan kehidupan setiap manusia. ${ }^{7}$ Berkaitan dengan topik Deskripsi "Sempurna Seperti Bapa" Sebagai Dasar Edukasi Pola Hidup Kristen juga pernah diteliti oleh Yakub Hendrawan Perangin Angin dan Tri Astuti Yeni Retnowati dengan penelitian Deskripsi Serupa Seperti Kristus Sebagai Tujuan Pendidikan Karakter Kristen. ${ }^{8}$ Kesimpulan dari artikel penelitian tersebut adalah bahwa Standar yang ditetapkan adalah serupa dengan Yesus. Tuntutan standar yang tinggi ini menuntut setiap orang Kristen menjalani hidup yang baru yang sama dengan gaya hidup Yesus. Orang Kristen sudah seharusnya berkarakter Kristus sesuai sebutan Kristen. Seri Damarwanti melakukan penelitian serupa dalam kajian yang ditekankan dalam prinsip Alkitab. Penelitian artikel berjudul Nilai Kesempurnaan Kristen dalam kitab Ibrani, dengan kesimpulan setiap orang percaya hendaknya memfokuskan hidup suci dan dalam keseluruhan hidupnya. ${ }^{9}$ Merujuk

Agama Kristen (JUPAK) 2, no. 1 (2021): 109126.

${ }^{8}$ Yakub Hendrawan Perangin Angin and Tri Astuti Yeniretnowati, "Deskripsi Serupa Seperti Kristus Sebagai Tujuan Pendidikan Karakter Kristen," ELEOS: Jurnal Teologi dan Pendidikan Agama Kristen 1, no. 1 (2021): 1327. 
kepada dua penelitian ini, maka peluang yang dapat diteliti selanjutnya, adalah: "Sempurna Seperti Bapa" Sebagai Dasar Edukasi Pola Hidup Kekristenan. Oleh sebab itu penelitian ini difokuskan pada judul Sempurna Seperti Bapa.

\section{METODE PENELITIAN}

Metode dalam penulisan jurnal ini adalah menggunakan metode kualitatif dengan pendekatan studi pustaka. ${ }^{10}$ Analisis dilakukan dengan cara meninjau berbagai buku teks dan jurnal yang sudah dilakukan sebelumnya, yaitu dengan cara menganalisis tentang konsep pola hidup yang sempurna seperti Bapa sebagai sebuah kerangka konsep standar dan pola hidup orang Kristen yang dapat digunakan sebagai panduan dalam menetapkan kebijakan arah bagi pengembangan dan Pendidikan Agama Kristen. Pada tahap awal peneliti melakukan pengelompokan buku-buku

dan artikel jurnal yang membahas topik sesuai dengan judul penelitian ini. Kedua Peneliti melakukan penggabungan dan kompilasi pokok-pokok bahasan yang

Kristen Dalam Kitab Ibrani," SANCTUM DOMINE: JURNAL TEOLOGI 4, no. 2 (2016): 19-28.

${ }^{10}$ Hamzah Amir, Metode Penelitian Kepustakaan, 1st ed. (Batu: Literasi Nusantara, 2020), 24.

${ }^{11}$ Sonny Eli Zaluchu, "Struktur Artikel sesuai. Ketiga, Peneliti membuat implikasi yang relevan dengan tema. Hasil kajian di atas selanjutnya diuraikan secara deskriptif dan sistematis. ${ }^{11}$ Penelitian ini diharapkan berkontribusi bagi penetapan kebijakan dan pengajaran terkait standar dan pola hidup orang Kristen yang memperagakan kehidupan sempurna seperti Bapa.

\section{HASIL DAN PEMBAHASAN}

\section{Sempurna Seperti Bapa (Mat. 5:48)}

Yesus mengajarkan bahwa keselamatan tidak lain merupakan proses dikembalikannya seseorang kepada desain Allah serupa dan segambar dengan diriNya. Dengan demikian, inti keselamatan adalah perubahan karakter menuju kesempurnaan. Orang percaya harus memiliki kualitas moral sempurna seperti Bapa (Mat. 5:48) dan saleh yang melebihi tokoh-tokoh agama mana pun (Mat. $5: 20) .^{12}$

Selanjutnya dalam Alkitab juga dinyatakan, bahwa; "Bagi mereka yang percaya, diberi kuasa supaya menjadi anak-anak Allah (Yoh. 1:12)”. Panggilan

Untuk Jurnal Ilmiah Dan Teknik Penulisannya," in Strategi Menulis Jurnal Untuk Ilmu Teologi, ed. Sonny Eli Zaluchu, 1st ed. (Semarang: Golden Gate Publishing Semarang, 2020), 1-21.

${ }^{12}$ Erastus Sabdono, Yesus Yang Lain, 1st ed. (Jakarta: Rehobot Literature, 2019). 
bagi setiap orang yang menaruh percaya kepada Kristus harus menggunakan kuasa yang sudah Allah berikan ini yang berarti untuk berkarakter seperti Allah atau sempurna seperti Bapa. ${ }^{13}$

Kehendak Allah bahwa setiap anak-anaknya memiliki kualitas moral Allah, yang ditandai dengan ciri: kudus seperti Allah kudus (1 Ptr. 1:16) dan mengenakan kodrat Ilahi (2 Ptr. 1:3-4). ${ }^{14}$ Orang Kristen fokus hidupnya menuju keserupaan seperti Yesus, agar dapat dilayakkan menjadi anggota keluarga Kerajaan Surga. ${ }^{15}$

Dalam Perjanjian Baru dijelaskan dengan sangat gamblang apa saja standar kualitas moral yang harus dicapai oleh setiap pengikut Kristus, yaitu: pertama, menjadi sempurna seperti Bapa, berkenan kepada Allah (2 Kor. 5:9-10). Kedua, serupa dengan Yesus (Flp. 2:5-7). Ketiga, hidup tidak bercacat dan tidak bercela (Flp. 1:10). Keempat, keadaan kudus seperti Bapa kudus (1 Ptr. 1:16). Kelima, mengambil bagian dalam kekudusan Allah (Ibr. 12:9-10). Keenam, mengenakan kodrat Ilahi (2 Ptr. 1:3-4). ${ }^{16}$ Dari keenam standar di atas, jelaslah bahwa setiap murid Kristus dituntut

\footnotetext{
${ }^{13}$ Erastus Sabdono, Penghakiman, 1st ed. (Jakarta: Rehobot Literature, 2019), 98-99.

${ }^{14}$ Erastus Sabdono, Datanglah Kerajaan-Mu, 1st ed. (Jakarta: Rehobot Literature, 2019).
}

menjadi sempurna seperti Bapa, yang selalu berusaha memperagakan tindakannya sesuai dengan pikiran dan perasaan Yesus. ${ }^{17}$

$$
\text { Untuk menjadi anggota warga }
$$
Kerajaan Surga dituntut karakter moral "seperti Bapa", pengikut Kristus hukumnya adalah Tuhan (The Lord is my law). Pengikut Kristus harus memiliki pikiran dan perasaan Kristus. ${ }^{18}$ Dalam perjalanan orang percaya perihal memiliki kesempurnaan Bapa sebagai standar orang percaya bukanlah sesuatu yang dapat ditawar lagi. Hal ini sangat jelas dikatakan oleh Tuhan Yesus dalam Matius 5:48 bahwa orang Kristen harus sempurna seperti Bapa adalah sempurna. Banyak di antara orang Kristen yang mendengar hal ini pesimis. Kata sempurna di sini sebenarnya tidak dapat serta merta diambil secara tekstual semata, karena memang tidak mungkin orang percaya memiliki sempurna seperti Allah dalam arti kekuasaan-Nya ataupun kemuliaan-Nya. Kesempurnaan di sini adalah dalam hal kehendak-Nya yang diletakkan dalam diri manusia secara khusus, yang tidak mungkin sama dengan orang lain. Kata sempurna dari bahasa asli adalah Teleios

\footnotetext{
${ }^{15}$ Sabdono, Bekal Kekekalan.

${ }^{16}$ Sabdono, Penghakiman.

${ }^{17}$ Erastus Sabdono, Tatanan Allah 2, 1st ed. (Jakarta: Rehobot Literature, 2019).

${ }^{18}$ Sabdono, Penghakiman.
} 
yang artinya sempurna, mencapai tujuan, utuh, lengkap, dan genap. Maksudnya adalah kehendak Bapa yang ada dalam diri orang percaya harus dikerjakan sampai lengkap. Orang percaya tidak akan pernah bisa mengukur sudah berapa lengkap, atau sudah berapa jauh berjalan, karena hanya Tuhan yang bisa memberi penilaian. Tugas pengikut Yesus hannyalah mengerjakan keselamatan dengan takut dan gentar (Flp. 2:12), sisanya serahkan kepada Tuhan. Sebuah kata yang penting dalam mengejar kesempurnaan atau kelengkapan adalah perjuangan. ${ }^{19}$

Sejak di bumi ini, orang Kristen harus sempurna seperti Bapa, sempurna yang dimaksud di sini adalah kesempurnaan manusia, dan Alkitab banyak berbicara tentang pokok ini, di antaranya (Mat. 5:48; Mat. 19:21; Yoh. 17:23; Rm. 12:2; 2 Kor. 10:6; 2 Kor. 13:9, 10; Flp. 3:12, 15; Kol. 1:9, 28; 1 Tes. 5:23; Ibr. 11:40; Ibr. 12:2, 23; Yak. 1:4; Yak. 2:22; Yak. 3:2; 1 Yoh. 4:18). ${ }^{20}$

Alkitab menunjukkan bahwa orang percaya harus mencapai kesempurnaan. Kesempurnaan masingmasing individu berbeda. Tuhan Yesus

\footnotetext{
${ }^{19}$ Stephen Erastus, "Sampai Di Mana Batasmu?," in Panggilan Khusus: Panggilan Untuk Menjadi Sempurna Seperti Bapa, ed. Tim Truth Literature, 1st ed. (Jakarta: Rehobot Literature, 2018), 57-58.

${ }^{20}$ Sabdono, Yesus Yang Lain.
}

bisa memerintahkan semua murid-Nya sempurna seperti Bapa. Di dalamnya, Tuhan memberi kemampuan kepada orang percaya untuk dapat melakukannya. Tidak mungkin Tuhan memerintahkan orang percaya untuk melakukan apa yang tidak dapat orang percaya lakukan. ${ }^{21}$

Selanjutnya Erastus Sabdono menjelaskan, bahwa: kesempurnaan dalam Tuhan, mengandung makna, iman yang sempurna seperti Yesus, dengan ciri ketaatan Yesus kepada Bapa di surga yang taat sampai mati (Ibr. 12:2-5). Orang Kristen yang fokus menjadi sempurna dalam perilakunya selalu dalam sikap berjaga, belajar terus mengerjakan semuanya sesuai seperti yang Allah inginkan di dalam keseluruhan aspekaspek hidupnya. ${ }^{22}$

\section{Aplikasi Pola Hidup Kristen Seharusnya}

\section{Memiliki Kecerdasan dan Ketelitian Rohani}

Tuhan menghendaki orang Kristen memiliki kecerdasan seperti Allah, yaitu kecerdasan rohani, suatu kemampuan untuk dapat memahami kehendak Allah. ${ }^{23}$

\footnotetext{
21 Ibid.

${ }^{22}$ Erastus Sabdono, Merdeka Dalam
} Tuhan, 1st ed. (Jakarta: Rehobot Literature, 2021).

${ }^{23}$ Erastus Sabdono, Selesai Sebelum Selesai, 1st ed. (Jakarta: Rehobot Literature, 
Orang Kristen harus cerdas secara rohani dan teliti memperhatikan seluruh hidupnya. Itu berarti orang percaya harus memeriksa diri dengan sangat serius dan saksama. Teliti dan cerdas rohani memperhatikan setiap gerak pikiran, perasaan, ucapan, dan perbuatan. Mestinya orang Kristen juga bisa tahu apa yang bisa menghancurkan hidup, yang bisa membahayakan hidup dan yang bisa membuat dirinya jatuh. Orang percaya harus memiliki tekad yang kuat untuk bisa menganalisis segala hal. ${ }^{24}$ Sebagai pengikut Kristus yang setia haruslah memiliki hasrat dan gairah untuk semakin sempurna seperti Bapa, dalam hal kecerdasan intelektual, emosi, dan rohani. $^{25}$

\section{Hidup Tidak Bercacat dan Tidak Bercela}

Setiap murid Kristus memiliki ambisi untuk selalu hidup tidak bercacat cela (1 Tes. 4:7) dan kudus seperti Bapa (1 Ptr. 1:13-17). Paulus berkata, "Aku berusaha untuk berkenan kepada Allah" (2 Kor. 5:9). Allah memanggil setiap anakanak-Nya bukan sekadar menjadi orang baik, namun menjadi sempurna. ${ }^{26}$

2021).

${ }^{24}$ Sabdono, Berjalan Dengan Allah.

${ }^{25}$ Erastus Sabdono, Penyesatan

Terselubung, 1st ed. (Jakarta: Rehobot Literature, 2016).
Orang percaya harus mengikuti dan menjalankan standar kesucian seperti Bapa. Sehingga kehidupan sebagai murid Yesus jika belum seperti Yesus, sudah jelas artinya belum sesuai dengan yang dikehendaki Allah. ${ }^{27}$

Hidup Dengan Memenuhi Tuntutan Allah

Setiap orang percaya, dituntut menjalani dan mengerjakan keselamatan yang sudah diperoleh dengan takut dan gentar (1 Ptr. 1:17; Flp. 2:12). Ketakutan di sini maksudnya takut kepada Allah sebagai Bapanya, takut yang karena mengasihi dan menghormati Allah. Karya penebusan Tuhan Yesus yang dilakukan di kayu salib dimaksudkan agar orang percaya menjadi seperti ungkapan popular ini, "Like Father like son". ${ }^{28}$

Bila hal ini dikorelasikan dengan Filipi 2:5-7, mengerjakan keselamatan berarti panggilan untuk memiliki pikiran dan perasaan Kristus, karena Yesus merupakan model manusia yang Allah kehendaki. Maka orang Kristen asli harus semakin seperti Kristus. ${ }^{29}$

\footnotetext{
${ }^{26}$ Sabdono, Tatanan Allah 2.

${ }^{27}$ Sabdono, Penghakiman.

${ }^{28}$ Sabdono, Penyesatan Terselubung.

${ }^{29}$ Erastus Sabdono, Penetapan, 1st ed.
} (Jakarta: Rehobot Literature, 2019). 
Hidup Dengan Iman yang Berkualitas

Definisi iman yang dimaksud di sini berarti menyerahkan diri kepada obyek yang dipercayai, sehingga seseorang yang mengikut Yesus Kristus sudah pasti terus menyerahkan diri untuk dipimpin Roh Kudus dalam melakukan apa yang diajarkan Yesus. untuk dikenakan dalam hidup ini. ${ }^{30}$ Dengan tingkat kualitas iman seperti ini menjadi kemutlakkan setiap orang Kristen untuk serupa seperti Yesus. $^{31}$ Kualitas kehidupan Kristen yang sehat dan benar, akan dicirikan dengan kehidupan yang intim bersama Tuhan, di mana kehadiran Tuhan sangat nyata mewarnai dan mempengaruhi gerak hidup orang percaya yang pasti kelihatan dan dirasakan orang lain. $^{32}$

Hidup yang Serupa Dengan Yesus

Kehidupan orang percaya merupakan proses yang terus berjalan sampai akhir hidupnya. Proses hidup merupakan bagian penting bagi setiap orang percaya. Hidup serupa seperti Yesus menjadi agenda utama pengikut

\footnotetext{
${ }^{30}$ Sabdono, Penghakiman, 94.

${ }^{31}$ Sabdono, Penghakiman.

${ }^{32}$ Erastus Sabdono, Philos, 1st ed. (Jakarta: Rehobot Literature, 2019).

${ }^{33}$ Stefanus Agus Budi Yanto and Paulus Kunto Baskoro, "Kajian Teologis Konsep Hidup Tekun Menurut Surat Yakobus 1: 2-8 Dan Aplikasinya Bagi Kehidupan Orang Percaya Pada
}

Kristus. ${ }^{33}$ Alkitab memberitahu bahwa tujuan hidup dalam Kristus adalah agar orang Kristen menjadi seperti Kristus. Yesus mengatakan kepada murid-muridNya, "siapa saja yang telah tamat pelajarannya akan sama dengan gurunya" (Luk. 6:40). Dengan kata lain, dengan mengikut Kristus, seseorang akan menjadi seperti Kristus. Bahkan tujuan gereja adalah untuk menolong orang kepada pencapaian kepenuhan Kristus (Ef. 4:13). Jadi, tujuan utama orang Kristen adalah keserupaan dengan Kristus. ${ }^{34}$ Tujuan utama Tuhan untuk kehidupan orang Kristen adalah perkembangan karakter, bertumbuh secara rohani menuju profil seperti Kristus. Tuhan ingin orang Kristen mengembangkan karakter yang diajarkan dalam khotbah di bukit (Mat. 5:1-12), buah-buah Roh (Gal. 5:22-23), kasih (1 Kor. 13), karakteristik kehidupan yang efektif dan produktif (2 Ptr. 1:5-8). ${ }^{35}$ Setiap orang Kristen dipanggil untuk menjadi sempurna seperti Bapa.

Paulus menyatakan bahwa orang percaya harus serupa seperti Yesus (Rm. 8:28-29), sebab Yesus adalah model manusia yang dikehendaki oleh Allah. ${ }^{36}$

\footnotetext{
Masa Kini," Ritornera-Jurnal Teologi Pentakosta Indonesia 1, no. 2 (2021): 37-60.

${ }^{34}$ Howard and William Hendricks, Seperti Besi Menajamkan Besi, 1st ed. (Yogyakarta: Yayasan Gloria, 2013), 144. ${ }^{35}$ Rick Warren, Untuk Apa Aku Ada Di Dunia Ini?, 15th ed. (Jakarta: Immanuel, 2021). ${ }^{36}$ Sabdono, Yesus Yang Lain.
} 
Ukuran kedewasaan dan kesempurnaan menurut Alkitab adalah "seperti Yesus".37 Pertumbuhan kedewasaan rohani dengan melibatkan peran Roh Kudus akan terusmenerus memperbaharui hasrat dan gairah orang percaya guna terus melekat kepada Allah. ${ }^{38}$ Analogi perjuangan Yesus dalam menyelesaikan tugas kemesiasan Yesus (Ibr. 12-2:4) dapat digunakan dalam orang Kristen meraih keadaan agar serupa seperti Yesus. ${ }^{39}$

Rick Warren menyatakan bahwa orang Kristen diciptakan untuk menjadi serupa seperti Kristus. ${ }^{40}$ Jadi tujuan hidup tertinggi yang dirancang Allah untuk seseorang adalah menjadi seperti Yesus. Kerinduan Allah adalah agar karakterkarakter Yesus nyata di dalam hidup orang Kristen. Paulus menyebut karakterkarakter ini sebagai "buah Roh". ${ }^{4}$

Diri Kristus adalah wujud nyata rancangan pertumbuhan Tuhan bagi manusia. Tuhan mau semua orang kembali menjadi serupa dan segambar dengan Diri-Nya, sebagaimana terwujud dalam Pribadi Kristus. Setiap orang yang percaya kepada pribadi dan karya Kristus

${ }^{37}$ Ibid.

${ }^{38}$ Yonatan Alex Arifianto, "Kajian Biblikal Tentang Manusia Rohani Dan Manusia Duniawi," Jurnal Teruna Bhakti 3, no. 1 (2020): 12-24.

${ }^{39}$ Sabdono, Penetapan.

${ }^{40}$ Warren, Untuk Apa Aku Ada Di Dunia Ini?

\footnotetext{
${ }^{41}$ Randy \& Robert Noland Frazee,
}

mengalami pemulihan gambar Allah. Sebagai manusia baru, orang Kristen memiliki potensi untuk bertumbuh menuju keserupaan dengan Kristus. Keserupaan dengan Kristus adalah sebuah proses perjalanan dengan campur tangan Tuhan. Allah menghendaki atau mengijinkan setiap keadaan dihadapi dan dilalui bagi pembentukan orang Kristen. Roh Kudus pun terus bekerja di dalam orang percaya untuk memperbaharui, memulihkan dan menguduskan. Inilah rancangan pertumbuhan bagi orang percaya. Sebagaimana di tulis Max Lucado dalam bukunya Just Like Jesus, "Tuhan mengasihi seseorang apa adanya, tetapi Dia tidak membiarkan seseorang seadanya. Dia akan mengubah orang percaya menjadi seperti Kristus." Tuhan tidak pernah berhenti merindukan seseorang menjadi serupa dan segambar dengan Dia, menjadi peniru kepribadianNya. Suatu kerinduan yang membuat orang percaya mendapatkan kepenuhan dan kepuasan hidup yang sesungguhnya. ${ }^{42}$ Paulus merindukan agar orang Kristen yang beriman dipenuhi oleh Roh Kudus

Berpikir, Bertindak, Menjadi Seperti Yesus, 1st ed. (Yogyakarta: Yayasan Gloria, 2016).

${ }^{42}$ Ajeng Chrissaningrum and Tim

Kambium Yayasan Gloria, Bertumbuh Dalam Kristus Pemuridan Melalui Waktu Teduh, ed. Petrus Budi Setyawan, Okdriati S. Handoyo, and Tri Puji Lestari, 1st ed. (Yogyakarta: Yayasan Gloria, 2012). 
sehingga sesungguhnya Kristus sendiri akan membentuk seluruh kehidupan orang percaya dari dalam ke luar. ${ }^{43}$ Kehidupan orang percaya yang menjadi serupa seperti Yesus adalah hidup seperti Dia hidup, bicara seperti Dia bicara, dan bersikap seperti Dia bersikap. ${ }^{44}$

\section{Hidup Sesuai Kehendak Allah}

Paulus menyatakan bahwa semua orang yang menyatakan percaya kepada Yesus Kristus harus memahami kehendak Allah (Rm. 12:1-2). Kesempurnaan berorientasi pada diri Allah sendiri, yaitu pada pikiran dan perasaan Allah, di mana segala sesuatu yang anak-anak Allah perbuat selaras dengan yang Allah mau. ${ }^{45}$ Seseorang yang tidak melaksanakan sesuai dengan yang Allah inginkan, tentunya belum dapat dikatakan orang Kristen. Maka, makna percaya di sini yaitu mengikuti jejak hidup Yesus, yaitu melakukan kehendak Bapa. ${ }^{46}$

Keselamatan orang percaya bukan hanya berakhir menjadikan Yesus sebagai Tuhan dan Juru selamat saja, melainkan

\footnotetext{
${ }^{43}$ Christopher J.H. Wright, Becoming Like Jesus, 1st ed. (Surabaya: Literatur Perkantas Jawa Timur, 2017), 10.

${ }^{44}$ Robby Gallaty, Rediscovering Discipleship, 1st ed. (Surabaya: Literatur Perkantas Jawa Timur, 2018), 73.

${ }^{45}$ Sabdono, Yesus Yang Lain.

${ }^{46}$ Eras Sabdono, Kehidupan Dalam Iman, 1st ed. (Jakarta: Rehobot Literature, 2018).

${ }^{47}$ Erastus Sabdono, Kehilangan Nyawa, 1st ed. (Jakarta: Rehobot Literature, 2021).
}

harus terus berlanjut kepada tahap dimuridkan, tahap pendewasaan rohani, dan bertumbuh agar menjadi seorang yang "melakukan kehendak Bapa". Hidup untuk Kristus berarti melakukan kehendak Bapa, sebab Yesus menjadi Tuhan bagi kemuliaan Allah. Dengan melakukan kehendak Bapa, seseorang benar-benar memuliakan Allah Bapa. ${ }^{47}$ Serta menjadi berkat dan dampak bagi sesama, karena sejatinya orang Kristen mewarisi kerinduan setiap orang mengenal Yesus Kristus dan diselamatkan. ${ }^{48}$

Hidup yang Berkenan Kepada Allah

Allah merancang dan menciptakan manusia sesuai tujuan Allah. Guna menuju tujuan yang sudah Allah tetapkan, manusia diberi kemampuan untuk berfungsi meraih dan menjalankan tujuan manusia dirancang. ${ }^{49}$ Paulus menyatakan terus mengejar kesempurnaan (Flp. 3:12) dan pada bagian lainnya dalam Alkitab, hampir senada bagaimana Paulus menyampaikan apa yang menjadi ambisinya ini dengan bahasa bahwa

\footnotetext{
${ }^{48}$ Sri Lina Betty Lamsihar Simorangkir and Yonatan Alex Arifianto, "Makna Hidup Dalam Kristus Menurut Filipi 1:21 Dan Implikasinya Bagi Orang Percaya," CARAKA: Jurnal Teologi Biblika dan Praktika 1, no. 2 (2020): 228-242.

${ }^{49}$ Joko Santoso, "Peran Keteladanan Pemimpin Dalam Keluarga Berdasarkan Efesus 5: 21-6: 4," SANCTUM DOMINE: JURNAL TEOLOGI 10, no. 2 (2021): 73-88.
} 
Paulus selalu berusaha untuk berkenan kepada Allah, atau dengan perkataan lain dapat diartikan selalu berusaha untuk mengejar kesempurnaan, sebagaimana kehendak Allah, agar sempurna seperti Bapa. Ambisinya ini, Paulus tuliskan dalam suratnya yang juga meminta semua para murid Yesus Kristus yang menyatakan iman percaya kepada Yesus Kristus agar selalu berusaha memahami kehendak Allah: yaitu apa yang baik, yang berkenan, dan yang sempurna. ${ }^{50}$

Rasul Paulus mengungkapkan kerinduan hatinya yaitu, agar Yesus Kristus dengan nyata dimuliakan di dalam tubuh Paulus (Flp. 1:20). Mencermati kalimat yang disampaikan oleh Paulus ini, dapat dilihat dengan jelas bagaimana Paulus berusaha menunjukkan keseriusan dan tanggung jawabnya atas panggilan Tuhan kepadanya, sehingga Paulus sangat memiliki komitmen yang sangat tinggi dalam mengiring dan melayani Tuhan. Paulus menyediakan diri untuk menjadi alat dalam menyatakan kemuliaan Kristus di sepanjang hidupnya melalui apa yang dilakukannya dan karya-karya pelayanannya. ${ }^{51}$

\footnotetext{
${ }^{50}$ Sabdono, Yesus Yang Lain.

${ }^{51}$ Sri Lina Betty Lamsihar Simorangkir and Yonatan Alex Arifianto, "Makna Hidup Adalah Kristus Berdasarkan Filipi 1: 21 Dan
}

\section{Hidup Dengan Pola Pikir Baru}

Status sebagai orang percaya yang beriman kepada Yesus Kristus, dituntut untuk mengenakan gaya yang pernah diperagakan oleh Kristus, baik dalam pikiran maupun perasaan sehingga hidup orang percaya adalah hidup yang mana Kristus yang hidup di dalam dirinya (Gal. 2:19-20). Kehidupan dengan gaya hidup yang terus-menerus pola pikirnya berubah sehingga dapat membedakan apa yang baik, benar dan bahkan yang sempurna (Rm. 12:1-2). Pada titik ini, orang Kristen layak mengaku seperti yang Paulus sampaikan, bahwa orang percaya telah mati dan hidup orang percaya yang dijalani adalah hidup yang tersembunyi bersama dengan Kristus di dalam Allah (Kol. 3:1-4). Sangat dalam sekali makna yang terkandung dalam firman Tuhan ini, di mana makna mati dapat diartikan "tidak lagi mengharapkan kesenangan dari dunia ini apa pun bentuk dan caranya”. Makna lainnya dari telah mati juga dapat dimaknai sebagai sikap dari orang percaya untuk "bersedia untuk tidak memiliki keinginan diri sendiri”. Kalaupun ada keinginan pada diri para murid Yesus Kristus semata-mata karena guna 
Kerajaan Allah dan kesukaan Allah. ${ }^{52}$ Banyak cara yang dapat dilakukan dalam peningkatan kualitas diri yang sempurna secara aktif, di antaranya adalah dengan menciptakan metode, program dan kegiatan serta kebiasaan baik dan sehat dengan penuh kreatifitas dan komitmen tinggi. ${ }^{53}$

Hidup Dengan Kelakuan yang Luar Biasa

Kehidupan orang percaya adalah kehidupan iman kepada Yesus Kristus yang diperagakan dengan kelakuan yang luar biasa. Perjuangan hidup untuk menjadi sempurna seperti Bapa merupakan usaha yang panjang dan harganya sangat mahal yang tidak akan berhenti sampai orang Kristen menutup mata. ${ }^{54}$ Orang Kristen dituntut baik dalam perkataan maupun dalam perbuatan dengan perilaku kesalehan yang terkenal baik (Mat. 5:20), tidak dapat ditawartawar lagi atau tidak dapat dikurangi bahwa standar Kristen yang benar adalah moral karakter seperti dinyatakan ayat di atas, yaitu moral orang Kristen yang menyatakan murid dan pengikut Yesus Kristus dituntut kualitasnya di atas rata-

\footnotetext{
52 Sabdono, Merdeka Dalam Tuhan.

${ }^{53}$ Joko Santoso, "Peningkatan Kualitas Diri Dalam Membangun Hubungan Antar Anggota Keluarga," Shift Key: Jurnal Teologi dan Pelayanan 8, no. 2 (2018).

${ }^{54}$ Sabdono, Merdeka Dalam Tuhan.
}

rata kualitas yang diperagakan oleh para tokoh agama dan rohani mana pun. ${ }^{55}$ Dalam kehidupan keluarga Kristen, para orang tua dituntut untuk sadar dan serius dalam membimbing, mengajar, dan menunaikan tanggung jawab pengasuhannya berdasarkan kebenaran firman Tuhan melalui keteladanan sehingga memberikan contoh kesalehan hidup bagi anak-anaknya. ${ }^{56}$ Secara praktis orang percaya dituntut memperagakan kesalehan yang mirip seperti Daniel di Perjanjian Lama. Tidak peduli betapa terlindungnya orang percaya pada masa kanak-kanak atau betapa seringnya orang percaya pergi ke gereja, akan tiba saatnya untuk memasuki dunia yang tidak mengenal Allah. Orang Kristen diperhadapkan baik di kota modern, di tempat kerja maupun di masyarakat pada gaya hidup yang berbeda secara radikal dari apa yang diajarkan Alkitab. Pada tiap saat orang percaya harus membuat keputusan-keputusan yang sulit. Tokoh Daniel dan teman-temannya dapat memberi contoh nyata yang sangat

\footnotetext{
${ }^{55}$ Erastus Sabdono, Pemilihan, 1 st ed. (Jakarta: Rehobot Literature, 2019).

${ }^{56}$ Joko Santoso, "Penerapan Pondasi Keluarga Bagi Generasi Penerus,” Jurnal Ilmiah Religiosity Entity Humanity (JIREH) 2, no. 2 (2020): 170-183.
} 
aplikatif baik bagi orang Kristen maupun komunitas orang percaya. Daniel merupakan bukti nyata keteladanan yang luar biasa saleh dalam kehidupan sehari-hari baik di lingkungan rumah, lingkungan komunitas, bahkan lingkungan jabatan yang sangat tinggi dengan berbagai kehormatan yang diberikan kepada Daniel. Daniel memperagakan pada orang percaya bagaimana cara menjalankan kehidupan rohani yang holistik di tengah berbagai tantangan tekanan dunia sekuler. ${ }^{57}$ Agar dapat menjadi teladan kesalehan, orang percaya harus dapat dipercaya. Orang Kristen dipanggil untuk dapat dipercaya, adil dan mau bertobat. Dengan kata lain, orang Kristen harus menjadi orang yang berintegritas. ${ }^{58}$

\section{KESIMPULAN}

Perjuangan untuk menjadi sempurna seperti Bapa sebenarnya tidak untuk mendapatkan keselamatan, melainkan wujud dari tanggung jawab atas pengorbanan dan kasih karunia yang sudah Yesus Kristus anugerahkan. Orang

${ }^{57}$ Douglas Connelly, Daniel Tetap Saleh Di Tengah Sekularitas 1, 3rd ed. (Jakarta: Literatur Perkantas, 2003), 8-9.
Kristen harus selalu berusaha untuk hidup sempurna sepanjang hidup. Kesempurnaan yang dimaksud sesuai dengan yang Allah kehendaki bagaimana orang percaya mengenakan apa yang terdapat di dalam Kristus yaitu yang dipikirkan dan perasaan-Nya. Kristus menjadi teladan, acuan dari manusia yang sempurna sebagaimana Allah inginkan. Untuk itu kehidupan orang Kristen sudah seharusnya hidup yang meneladani bagaimana Yesus hidup.

Aplikasi yang dapat dilakukan sebagai panduan pola hidup kekristenan orang percaya paling tidak harus memperagakan beberapa hal ini, yaitu: Pertama, Memiliki kecerdasan dan ketelitian rohani. Kedua, Hidup tidak bercacat dan tidak bercela. Ketiga, Hidup dengan memenuhi tuntutan Allah. Keempat, Hidup dengan iman yang berkualitas. Kelima, Hidup yang serupa dengan Yesus. Keenam, Hidup sesuai kehendak Allah. Ketujuh, Hidup yang berkenan kepada Allah. Kedelapan, Hidup dengan pola pikir baru. Kesembilan, Hidup dengan kelakuan yang luar biasa.

\section{DAFTAR PUSTAKA}

Amir, Hamzah. Metode Penelitian Kepustakaan. 1st ed. Batu: Literasi

${ }^{58}$ Matt Chandler and Adam Griffin, Family Discipleship (Pemuridan Keluarga), 1st ed. (Yogyakarta: Katalis, 2021), 74. 
Nusantara, 2020.

Angin, Yakub Hendrawan Perangin, and Tri Astuti Yeniretnowati. "Deskripsi Serupa Seperti Kristus Sebagai Tujuan Pendidikan Karakter Kristen." ELEOS: Jurnal Teologi dan Pendidikan Agama Kristen 1, no. 1 (2021): 13-27.

Arifianto, Yonatan Alex. "Kajian Biblikal Tentang Manusia Rohani Dan Manusia Duniawi." Jurnal Teruna Bhakti 3, no. 1 (2020): 12-24.

Chandler, Matt, and Adam Griffin. Family Discipleship (Pemuridan Keluarga). 1st ed. Yogyakarta: Katalis, 2021.

Chrissaningrum, Ajeng, and Tim Kambium Yayasan Gloria. Bertumbuh Dalam Kristus Pemuridan Melalui Waktu Teduh. Edited by Petrus Budi Setyawan, Okdriati S. Handoyo, and Tri Puji Lestari. 1st ed. Yogyakarta: Yayasan Gloria, 2012.

Connelly, Douglas. Daniel Tetap Saleh Di Tengah Sekularitas 1. 3rd ed. Jakarta: Literatur Perkantas, 2003.

Damarwanti, Seri. "Nilai Kesempurnaan Kristen Dalam Kitab Ibrani." SANCTUM DOMINE: JURNAL TEOLOGI 4, no. 2 (2016): 19-28.

Erastus, Stephen. "Sampai Di Mana Batasmu?" In Panggilan Khusus: Panggilan Untuk Menjadi Sempurna Seperti Bapa, edited by Tim Truth Literature, 57-60. 1st ed. Jakarta: Rehobot Literature, 2018.

Frazee, Randy \& Robert Noland. Berpikir, Bertindak, Menjadi Seperti Yesus. 1st ed. Yogyakarta: Yayasan Gloria, 2016.

Gallaty, Robby. Rediscovering Discipleship. 1st ed. Surabaya: Literatur Perkantas Jawa Timur, 2018.
Howard, and William Hendricks. Seperti Besi Menajamkan Besi. 1st ed. Yogyakarta: Yayasan Gloria, 2013.

Hull, Bill. Choose The Life. 2nd ed.

Surabaya: Literatur Perkantas Jawa Timur, 2015.

Sabdono, Erastus. Kehidupan Dalam Iman. 1st ed. Jakarta: Rehobot Literature, 2018.

Sabdono, Erastus. Bekal Kekekalan. 1st ed. Jakarta: Rehobot Literature, 2019.

Berjalan Dengan Allah. 1st ed. Jakarta: Rehobot Literature, 2021. Datanglah Kerajaan-Mu. 1st ed. Jakarta: Rehobot Literature, 2019. Kehilangan Nyawa. 1st ed. Jakarta: Rehobot Literature, 2021. Merdeka Dalam Tuhan. 1st ed. Jakarta: Rehobot Literature, 2021.

__. "Panggilan Khusus." In Panggilan Khusus: Panggilan Untuk Menjadi Sempurna Seperti Bapa, edited by Tim Truth Literature, 1-4. 1st ed. Jakarta: Rehobot Literature, 2018.

- Pemilihan. 1st ed. Jakarta:

Rehobot Literature, 2019.

- Penetapan. 1st ed. Jakarta:

Rehobot Literature, 2019. Penghakiman. 1st ed. Jakarta: Rehobot Literature, 2019.

Penyesatan Terselubung. 1st ed. Jakarta: Rehobot Literature, 2016. . Philos. 1st ed. Jakarta: Rehobot Literature, 2019. . Selesai Sebelum Selesai. 1st ed. Jakarta: Rehobot Literature, 2021. . Tatanan Allah 2. 1st ed. Jakarta: Rehobot Literature, 2019. Yesus Yang Lain. 1st ed. Jakarta: Rehobot Literature, 2019. 
Santoso, Joko. "Penerapan Pondasi Keluarga Bagi Generasi Penerus." Jurnal Ilmiah Religiosity Entity Humanity (JIREH) 2, no. 2 (2020): 170-183.

. "Peningkatan Kualitas Diri Dalam Membangun Hubungan Antar Anggota Keluarga." Shift Key: Jurnal Teologi dan Pelayanan 8, no. 2 (2018).

- "Peran Keteladanan Pemimpin Dalam Keluarga Berdasarkan Efesus 5: 21-6: 4." SANCTUM DOMINE: JURNAL TEOLOGI 10, no. 2 (2021): 73-88.

Simorangkir, Sri Lina Betty Lamsihar, and Yonatan Alex Arifianto. "Makna Hidup Adalah Kristus Berdasarkan Filipi 1: 21 Dan Implikasinya Bagi Orang Percaya." CARAKA: Jurnal Teologi Biblika dan Praktika 1, no. 2 (2020): 228242.

"Makna Hidup Dalam Kristus Menurut Filipi 1:21 Dan Implikasinya Bagi Orang Percaya." CARAKA: Jurnal Teologi Biblika dan Praktika 1, no. 2 (2020): 228242.

Triposa, Reni, Yonatan Alex Arifianto, and Yudi Hendrilia. "Peran Guru PAK Sebagai Teladan Dalam Meningkatkan Kerohanian Dan Karakter Peserta Didik." Jurnal Pendidikan Agama Kristen (JUPAK) 2, no. 1 (2021): 109-126.

Warren, Rick. Untuk Apa Aku Ada Di Dunia Ini? 15th ed. Jakarta: Immanuel, 2021.

Wright, Christopher J.H. Becoming Like Jesus. 1st ed. Surabaya: Literatur Perkantas Jawa Timur, 2017.

Yanto, Stefanus Agus Budi, and Paulus Kunto Baskoro. "Kajian Teologis Konsep Hidup Tekun Menurut Surat Yakobus 1: 2-8 Dan Aplikasinya
Bagi Kehidupan Orang Percaya Pada Masa Kini." Ritornera-Jurnal Teologi Pentakosta Indonesia 1, no. 2 (2021): 37-60.

Zaluchu, Sonny Eli. "Struktur Artikel Untuk Jurnal Ilmiah Dan Teknik Penulisannya." In Strategi Menulis Jurnal Untuk Ilmu Teologi, edited by Sonny Eli Zaluchu, 1-21. 1st ed. Semarang: Golden Gate Publishing Semarang, 2020. 
70 | SANCTUM DOMINE: Jurnal Teologi, vol. 11, no. 1 (2021) 